Article

\title{
Fatty Acids from Ganoderma lucidum Spores: Extraction, Identification and Quantification
}

\author{
Maria Michela Salvatore ${ }^{1} \mathbb{D}$, Alessandro Elvetico ${ }^{1}$, Monica Gallo ${ }^{2} \mathbb{D}$, Francesco Salvatore ${ }^{1}$, \\ Marina DellaGreca ${ }^{1}$, Daniele Naviglio ${ }^{1, *}$ (D) and Anna Andolfi ${ }^{1, *(D)}$ \\ 1 Department of Chemical Sciences, University of Naples 'Federico II', 80126 Naples, Italy; \\ mariamichela.salvatore@unina.it (M.M.S.); alessandro.elvetico@yahoo.it (A.E.); frsalvat@unina.it (F.S.); \\ dellagre@unina.it (M.D.) \\ 2 Department of Molecular Medicine and Medical Biotechnology, University of Naples 'Federico II', \\ 80131 Naples, Italy; mongallo@unina.it \\ * $\quad$ Correspondence: naviglio@unina.it (D.N.); andolfi@unina.it (A.A.); Tel.: +39-081-2539179 (A.A.)
}

Received: 19 May 2020; Accepted: 27 May 2020; Published: 5 June 2020

check for updates

Featured Application: This study sought to contribute to the improvement of the extraction, identification and quantification of the fatty acids component in Ganoderma lucidum spores in order to find simple and non-expensive tools for laboratory studies aiming at future applications, such as the easy comparison of lipids produced by different strains at diverse growth conditions.

\begin{abstract}
Ganoderma lucidum is a rich and promising source of bioactive compounds capable of positively influencing the human health. For this reason, G. lucidum is the target of vigorous investigational activities, focusing on the extraction of substances with potential biomedical applications, as well as on the improvement of analytical methodologies for their screening. In the present study, three different extraction processes (i.e., extraction with $n$-hexane, in Soxhlet apparatus with $n$-hexane and reflux with chloroform) were employed to evaluate the lipid content of G. lucidum spores. The experimental data from the produced extracts were compared with ones from the commercial liquid extract obtained with supercritical $\mathrm{CO}_{2}$ extraction of G. lucidum spores. To achieve this goal, the gas chromatography-mass spectrometry (GC-MS) methodology was optimized for an accurate and reliable identification and quantification of fatty acids in triglycerides of G. lucidum spores. Significant amounts of oleic and palmitic acids were found in the examined extracts. In particular, our findings show that economical and convenient extraction procedures, which are simple, low cost and no need for expensive tools, allow to produce extracts with a lipid composition similar to the one obtained with hard strategies of extraction.
\end{abstract}

Keywords: Ganoderma; bioactive compounds; GC-MS; triglycerides; mushroom; fatty acids

\section{Introduction}

Ganoderma lucidum is a saprophytic mushroom belonging to the Basidiomycetes phylum, which has been extensively used in oriental medical culture for the general promotion of health and longevity. In fact, it is considered the "immortality mushroom" in China, Japan, Korea and other Asian countries [1,2]. It has received an increasing attention in mycological research for the biomedical applications of the fruiting bodies, cultured mycelia and spores [3]. In fact, it has been used in the treatment of diverse human diseases including allergy, insomnia, inflammation, fungal, bacterial and viral infections, hypertension and cancer [4-6]. The numerous pharmacological effects of this mushroom may be related to its ability to produce various bioactive substances, such as proteins, polysaccharides, 
triterpenes, nucleosides, triglycerides and mineral salts [7-11]. Although the bioactivity of the spores may be higher than that of fruiting body [12], spores were recognized and utilized only in the last century [13]. For this reason, the spores of G. lucidum have been rarely studied, but over the last decade this important source of bioactive compounds is receiving an increasing attention from the scientific community [14].

The bioavailability of active compounds in the spores depends on the status of sporoderm. In fact, the spores are protected by a double chitin wall and this polysaccharidic barrier prevents a correct digestion by the human and, consequently, the absorption of the macro- and micronutrients present in the spores. Hence, a crucial step is the break of the sporoderm because there are fewer pharmacological effects observed when the sporoderm is not broken [15]. With the development of spore collection, sporoderm-broken technology and modern analytical technology, many constituents were identified in G. lucidum spores. Moreover, the quality and content of bioactive compounds vary from strain-to-strain, and may be affected by culture conditions and processing procedures [4]. Enriching the existing literature with new data on compounds produced by different isolates and on the strategy to extract them, especially from spores, may be valuable for the use of G. lucidum in the biomedical field. Although a few investigators have already studied the fatty acids in the triglycerides from G. lucidum [16], in general referred to the fruiting body [17], there are few information on the extraction processes.

In the present study, three different processes were employed in order to perform a reliable and accurate identification and quantification of the lipid content of the spores of G. lucidum. Nuclear magnetic resonance (NMR) spectroscopy investigation was conducted on oily extracts of G. lucidum obtained in Soxhlet apparatus with $n$-hexane, to reflux with chloroform and with $n$-hexane at room temperature. The data of the extraction processes were compared with the data obtained from the commercially available liquid extract from supercritical $\mathrm{CO}_{2}$ extraction of G. lucidum spores. Triglycerides were submitted to a common transesterification reaction in order to obtain fatty acid methyl esters (FAMEs) and finally identified and quantified by gas chromatography-mass spectrometry (GC-MS). Particularly relevant in the present work is the optimization of the GC-MS methodology to provide the best peak resolution and minimum run time for FAMEs identification and quantification.

\section{Materials and Methods}

\subsection{General Experimental Procedures}

NMR spectra were recorded at $400 \mathrm{MHz}$ in $\mathrm{CDCl}_{3}$ on a Bruker spectrometer (AscendTM400) (Rheinstetten, Germany). All reagents and solvents were analytical grade and purchased from Carlo Erba (Milan, Italy), Sigma-Aldrich (Saint Louis, MO, USA) and Fluka (Buchs, Switzerland).

The GC-MS analysis for fatty acids methyl esters (FAMEs) was performed with an Agilent 6850 GC equipped with an HP-5MS capillary column (5\% phenyl methyl polysiloxane stationary phase) and the Agilent 5973 Inert MS detector (Milan, Italy) (used in the scan mode). The flow rate of helium carrier gas was kept at $1 \mathrm{~mL} \mathrm{~min}^{-1}$.

Solutions of standard compounds were prepared in $n$-hexane at a concentration range of about 25-150 $\mathrm{mg} \mathrm{L}^{-1}$ and analyzed by GC-MS. Methyl ester of nonanoic acid (Sigma-Aldrich, Saint Louis, MO, USA) was used as internal standard (IS), a stock solution of which in $n$-hexane at concentration of $1 \mathrm{~g} \mathrm{~L}^{-1}$ was prepared and stored at $-20^{\circ} \mathrm{C}$.

\subsection{Spore Source}

The spores of G. lucidum were supplied by ItalianWay (Verbano, Italy) and cultivated using the traditional method within the DaXingAnLing natural park region, in China. The manufacturing company guaranteed $95 \%$ spore opening.

Liquid extract of spores of G. lucidum obtained using supercritical $\mathrm{CO}_{2}$ extraction was supplied by ItalianWay. 


\subsection{Extraction of the Lipid Component}

\subsubsection{Extraction with $n$-Hexane}

$20 \mathrm{~g}$ of spores of G. lucidum were suspended in $50 \mathrm{~mL}$ of $n$-hexane, at room temperature, under magnetic stirring and in the dark for $30 \mathrm{~min}$. The suspension was filtered and the exhausted was recovered to repeat the extraction process in the same condition. The organic phases were combined and the solvent evaporated under reduced pressure.

\subsubsection{Extraction in Soxhlet Apparatus with $n$-Hexane}

$100 \mathrm{~g}$ of spores of G. lucidum were placed in a thimble of filter paper and extracted with $450 \mathrm{~mL}$ of $n$-hexane for $18 \mathrm{~h}$ for a total of 720 cycles. At the end, the organic phase was filtered and evaporated under reduced pressure. The experiment was carried out in duplicate.

\subsubsection{Reflux Extraction with Chloroform}

$1 \mathrm{~g}$ of spores of G. lucidum were suspended in $30 \mathrm{~mL}$ of chloroform. The mixture was heated to reflux for $2 \mathrm{~h}$, set to cool and filtered under reduced pressure. The exhausted was recovered and extracted in the same condition. The organic phases were then combined, and the solvent evaporated under reduced pressure. The experiment was carried out in duplicate.

\subsection{Sample Preparation}

NMR data suggest the presence, as main components, of triglycerides in the commercial sample of G. lucidum and in the extracts obtained as reported in previous sections. The triglycerides were submitted to a transesterification reaction with methanol in the presence of a basic catalyst (i.e., potassium hydroxide), as described by [18]. In this way, the fatty acids chains are released from glycerol skeleton and recombine with the alcohol to yield fatty acids methyl esters (FAMEs).

\subsection{Qualitative and Quantitative Analysis of the Lipid Components}

FAMEs were identified via GC-MS by Kovats non-isothermal retention indices (KI) and comparing their mass spectra with those present in databases by employing the National Institute of Standards and Technology (NIST) Mass Spectral Search Program v.2.0 g which explores the NIST 14 Mass Spectral library (2014) [19]. Kovats indices of FAMEs were calculated by the Kovats equation, using the standard $n$-alkane mixture in the range C7-C40 (Sigma-Aldrich) [20].

The FAME quantification was carried out with a calibration curve five points in the range of about 25-150 $\mathrm{mg} \mathrm{L}^{-1}$ using methyl ester of nonanoic acid as internal standard at the constant concentration of $122.4 \mathrm{mg} \mathrm{L}^{-1}$ [20]. The concentrations of individual FAME in each sample were converted to percentage contributions of the total FAMEs [21].

\subsection{Optimization of GC-MS Method}

The optimization of instrumental parameters was performed using standard mixture of 37 FAMEs, purchased by Sigma-Aldrich, and added with internal standard (methyl ester of nonanoic acid). In order to avoid compounds co-elution which may provide identification and quantification problems, the separation of FAMEs in the chromatogram was optimized. The optimal injector temperature was $250^{\circ} \mathrm{C}$ and during the run a temperature ramp raised the column temperature from $50^{\circ} \mathrm{C}$ to $240{ }^{\circ} \mathrm{C}$ : the initial column temperature was $50^{\circ} \mathrm{C}$ and held for $2 \mathrm{~min}$, ramped to $180^{\circ} \mathrm{C}$ at the rate of $10^{\circ} \mathrm{C} \mathrm{min}-1$ and held $5 \mathrm{~min}$ and then finally increased to $240^{\circ} \mathrm{C}$ at the rate of $5^{\circ} \mathrm{C} \mathrm{min}-1$, held $25 \mathrm{~min}$. The ionization was carried out with the electron impact (EI) ion source at $70 \mathrm{eV}$ and at $200^{\circ} \mathrm{C}$. The quadrupole mass filter was kept at $250{ }^{\circ} \mathrm{C}$ and, in the scan mode, was programmed from 45 to $550 \mathrm{~m} / \mathrm{z}$ with a frequency of $3.9 \mathrm{~Hz}$. The detectability of compounds in the matrix is significantly improved with deconvolution. 
This function is supported by the NIST deconvolution program automated mass spectral deconvolution \& identification system (AMDIS) [22,23].

\section{Results}

The extraction processes of Ganoderma lucidum spores gave oily residues, as reported in experimental section. The extracts weights obtained by extraction with $n$-hexane, in Soxhlet apparatus with $n$-hexane and reflux extraction with chloroform are, respectively, $5.3 \pm 0.31 \mathrm{~g}$ (yield $=26.43 \%$ ), $32.7 \pm 0.24 \mathrm{~g}$ (yield $=32.65 \%$ ) and $0.27 \pm 0.02 \mathrm{~g}$ (yield $=26.83 \%$ ). The oily extracts were submitted to spectroscopic investigations via NMR. The ${ }^{1} \mathrm{H}$ NMR spectra showed typical signals of triglycerides containing chains of saturated and unsaturated fatty acids [24]. Moreover, even in the commercially available liquid extract of G. lucidum. In fact, their proton spectra showed the signals related to fatty acid residues at $\delta: 5.46-5.33(\mathrm{~m},-\mathrm{CH}=\mathrm{CH}-) ; 2.78$ (brt, $\left.J=6.6, \mathrm{~Hz},=\mathrm{CH}-\mathrm{CH}_{2}-\mathrm{CH}=\right) ; 2.37-2.29(\mathrm{~m}$, -O-CO-CH $\left.{ }_{2}\right) ; 2.16-1.70\left(\mathrm{~m}, \mathrm{CH}_{2}-\mathrm{CH}=\mathrm{CH}-\right) ; 1.67-1.62\left(\mathrm{~m},-\mathrm{O}-\mathrm{CO}-\mathrm{CH}_{2}-\mathrm{CH}_{2}-\right) ; 1.39-1.21\left(\mathrm{~m},-\left(\mathrm{CH}_{2}\right)_{\mathrm{n}^{-}}\right)$; 0.93-0.88 (m, $\left.\mathrm{CH}_{3} \mathrm{CH}_{2}-\right)$ and of residue of glycerols triesterified at $\delta: 5.28(\mathrm{tt}, J=4.0,6.0 \mathrm{~Hz}$, $\left.\mathrm{ROCH}_{2}-\mathrm{CHOR}^{\prime}-\mathrm{CH}_{2} \mathrm{OR}{ }^{\prime \prime}\right) ; 4.30\left(\mathrm{dd}, J=4.0,12.0 \mathrm{~Hz}, \mathrm{ROCH}_{2 \mathrm{~A}}-\mathrm{CHOR}^{\prime}-\mathrm{CH}_{2 \mathrm{~A}} \mathrm{OR}{ }^{\prime \prime}\right) ; 4.15(\mathrm{dd}, J=6.0$, $12.0 \mathrm{~Hz}, \mathrm{ROCH}_{2 \mathrm{~B}}-\mathrm{CHOR}^{\prime}-\mathrm{CH}_{2 \mathrm{~B}} \mathrm{OR}$ ") (Figure 1).

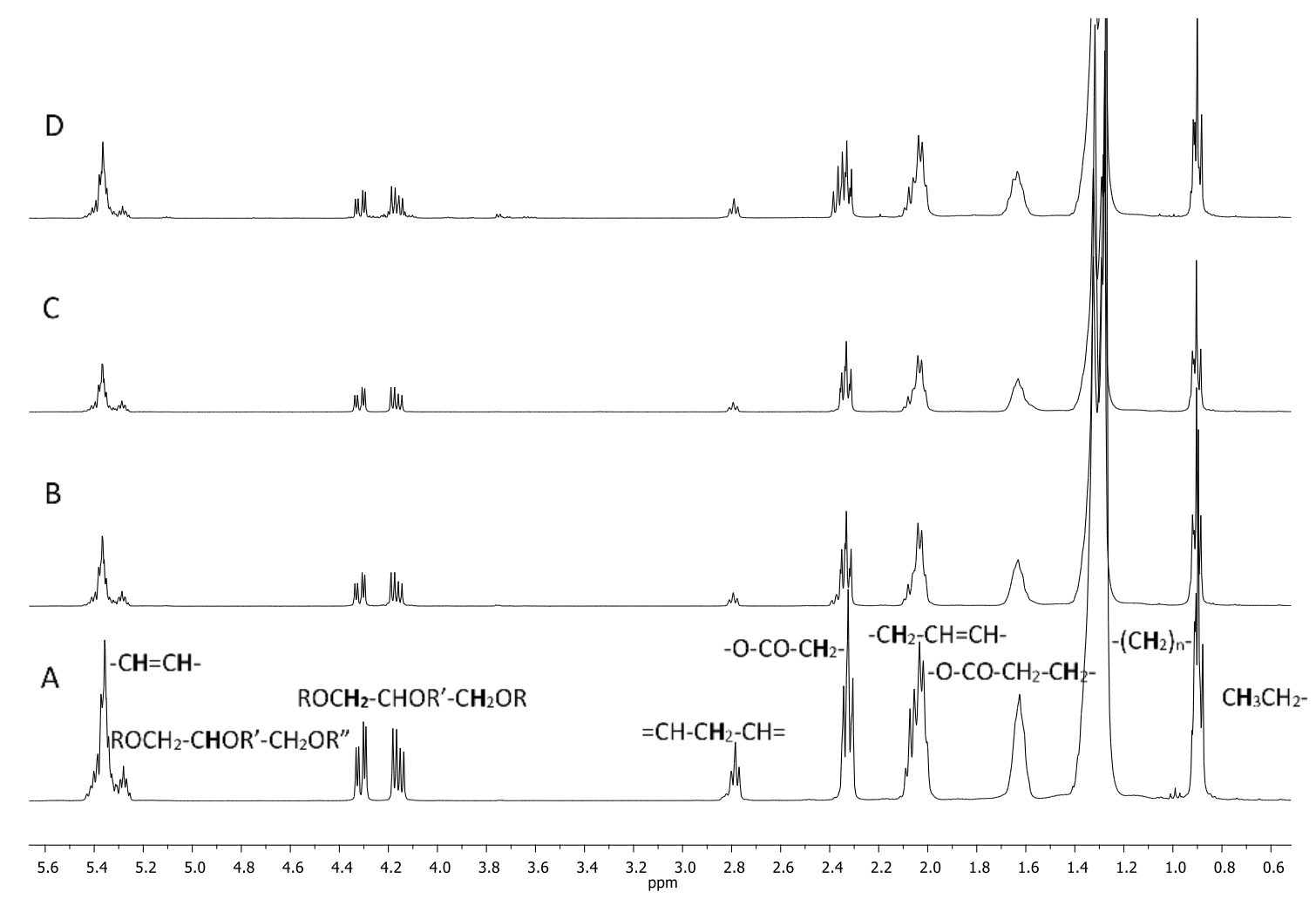

Figure 1. ${ }^{1} \mathrm{H}$ NMR spectra recorded at $400 \mathrm{MHz}$ in $\mathrm{CDCl}_{3}$ of extracts obtained from Ganoderma lucidum spores: (A) commercial liquid extract; (B) by $n$-hexane; (C) by $n$-hexane in Soxhlet apparatus; (D) by reflux in $\mathrm{CHCl}_{3}$.

Triglycerides in the oily extracts of G. lucidum were subjected to a common transesterification reaction, called alcoholysis. In transesterification, triglycerides react with methanol in the presence of a basic catalyst to form a mixture of glycerol and fatty acid methyl esters (FAMEs) [18]. FAMEs were identified and quantified via GC-MS in all samples.

For accurate identification and quantification of FAMEs, the GC-MS method was optimized for the best peak resolution and minimum run time using a 37-components FAMEs standard mixture. As can be seen from Figure 2, the optimized method (reported in a previous section) provides separation on 
the base line of all components of the standard FAMEs mixture. In Table 1 are exposed retention data both in the form of retention times $\left(t_{r}\right)$ and Kovats retention indices (KI) of the twelve FAMEs obtained from G. lucidum spores.

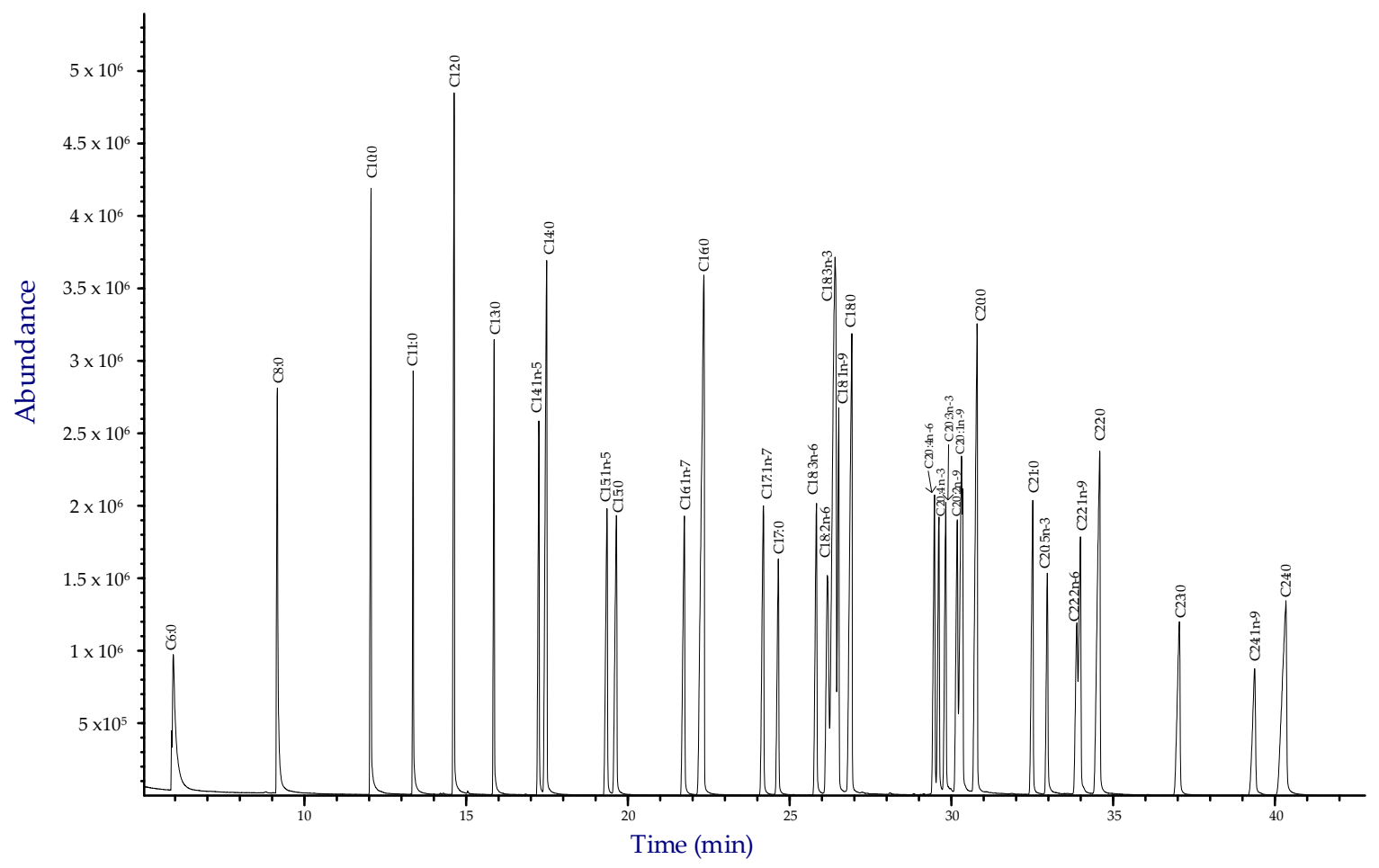

Figure 2. Total ion chromatogram (TIC) of a standard mixture of fatty acid methyl esters (FAMEs) obtained with the optimized method.

Table 1. Performance data of the optimized gas chromatography-mass spectrometry (GC-MS) separation and quantification method.

\begin{tabular}{|c|c|c|c|c|c|c|c|c|}
\hline & Name * & $t_{r}(\min )$ & KI & $\begin{array}{c}\text { Intercept } \\
\left(a \pm s_{a}\right)\end{array}$ & Slope $\left(b \pm s_{b}\right) \mathrm{L} \mathrm{mg}^{-1}$ & $\mathbf{R}^{2}$ & $\begin{array}{c}\text { LOD } \\
\left(\mathrm{mg} \mathrm{L}^{-1}\right)\end{array}$ & $\begin{array}{c}\text { LOQ } \\
\left(\mathrm{mg} \mathrm{L}^{-1}\right)\end{array}$ \\
\hline C14:0 & Myristic acid & 17.42 & 1720 & $0.000 \pm 0.024$ & $0.01306 \pm 0.00032$ & 0.998 & 6.0 & 18.3 \\
\hline $\mathrm{C} 16: 1 \mathrm{n}-7$ & Palmitoleic acid & 22.00 & 1916 & $-0.0095 \pm 0.0093$ & $0.00665 \pm 0.00012$ & 0.999 & 4.7 & 14.3 \\
\hline $\mathrm{C} 16: 0$ & Palmitic acid & 22.51 & 1936 & $-0.005 \pm 0.024$ & $0.01408 \pm 0.00026$ & 0.998 & 5.6 & 17.1 \\
\hline$C 18: 2 n-6$ & Linoleic acid & 25.18 & 2094 & $-0.0148 \pm 0.0093$ & $0.00686 \pm 0.00011$ & 0.999 & 4.5 & 13.6 \\
\hline C18:1n-9 & Oleic acid & 26.81 & 2124 & $-0.018 \pm 0.045$ & $0.02674 \pm 0.00057$ & 0.998 & 5.6 & 16.8 \\
\hline $\mathrm{C} 18: 0$ & Stearic acid & 27.14 & 2140 & $0.000 \pm 0.025$ & $0.0149 \pm 0.00033$ & 0.998 & 5.6 & 16.9 \\
\hline C20:1n-9 & Gadoleic acid & 30.24 & 2299 & $-0.021 \pm 0.019$ & $0.00793 \pm 0.00025$ & 0.996 & 7.9 & 24.0 \\
\hline
\end{tabular}

* fatty acids were analyzed via GC-MS as methyl esters.

For quantification of detected FAMEs, the internal standard calibration method (ISTD) was employed, as is usual in quantitative GC-MS work.

To this end, the standard FAMEs mixture was diluted with $n$-hexane to prepare five calibration solutions containing accurately known concentrations of each target analyte. Furthermore, each calibration solution was made $122.4 \mathrm{mg} \mathrm{L}^{-1}$ of methyl ester of nonanoic acid internal standard (IS). 
For each target analyte, a calibration plot was constructed by reporting (at each calibration level) the area of its chromatographic peak, normalized with the area of the IS peak, as a function of the known concentration of the analyte $\left(\mathrm{mg} \mathrm{L}^{-1}\right)$. The signal of a reagent blank containing only the IS in $n$-hexane was also measured as control during calibration.

Visual inspection of each calibration plot readily showed a linear dependence of the normalized signal from the concentration. In fact, calibration data could be excellently interpolated with a least square regression line $(y=a+b x)$ in which $a$ represents the intercept and $b$ the slope $\left(\mathrm{L} \mathrm{mg}^{-1}\right)$ of the least square line through the calibration points. This is easily deduced from the determination coefficient $\left(R^{2}\right)$ reported in Table 1 which is very close to one.

In Table 1 are also reported intercepts and slopes deduced from the twelve calibration plots together with the corresponding standard deviations (respectively, $s_{a}$ and $s_{b}$ ) which were calculated from the calibration data according to standard statistical procedures [25].

The standard deviation of the intercept, $s_{a}$, is then used to calculate the method detection limit (LOD) according to the formula: $\mathrm{LOD}=3.3 \times s_{a} / b$; and the quantification limit (LOQ) according to the formula: $\mathrm{LOQ}=10 \times s_{a} / b[25]$.

In Figure 3 are compared total ion chromatograms (TICs) of the three extracts of G. lucidum spores obtained in this study with different processes (Figure 3A-C) and the commercial liquid extract of G. lucidum spores obtained using supercritical $\mathrm{CO}_{2}$ extraction (Figure 3D).

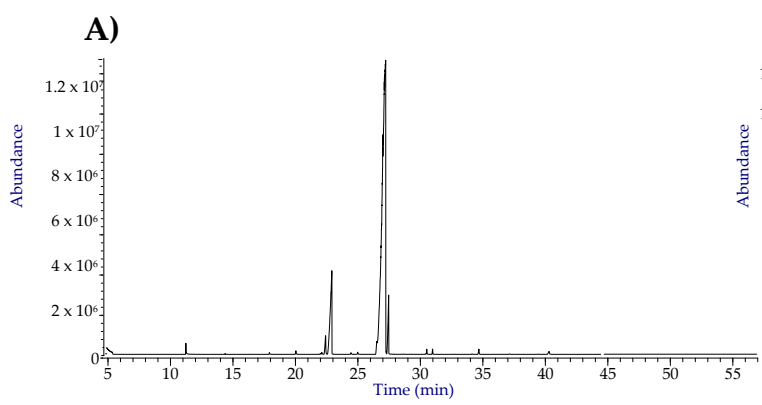

C)

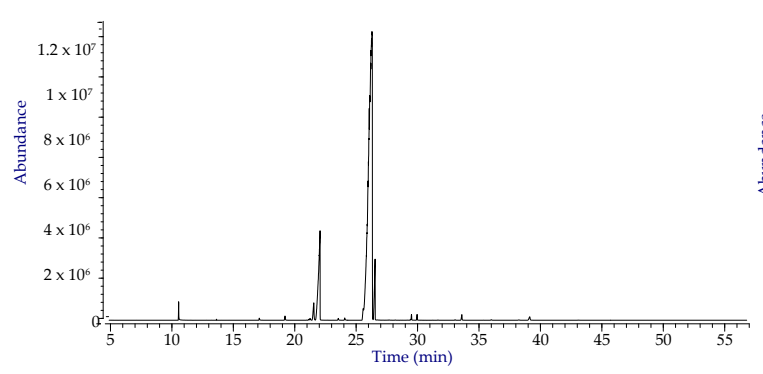

B)

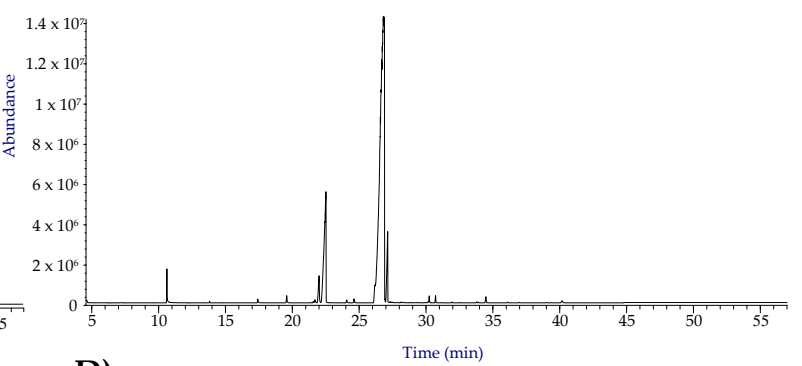

D)

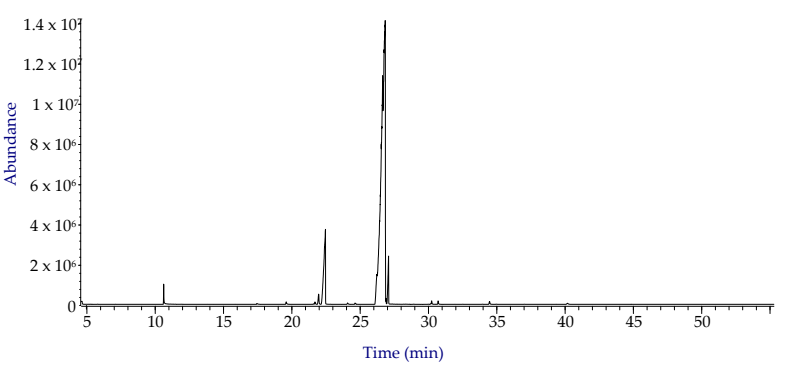

Figure 3. Total ion chromatograms (TICs) profiles of FAMEs obtained after transesterification of triglycerides contained in samples of Ganoderma lucidum extracted with different processes: (A) extraction with $n$-hexane; (B) extraction in Soxhlet apparatus with $n$-hexane; (C) reflux extraction with chloroform; (D) commercial oil.

An example of annotated TIC relative to fatty acids contained in samples of G. lucidum spores is shown in Figure 4. 


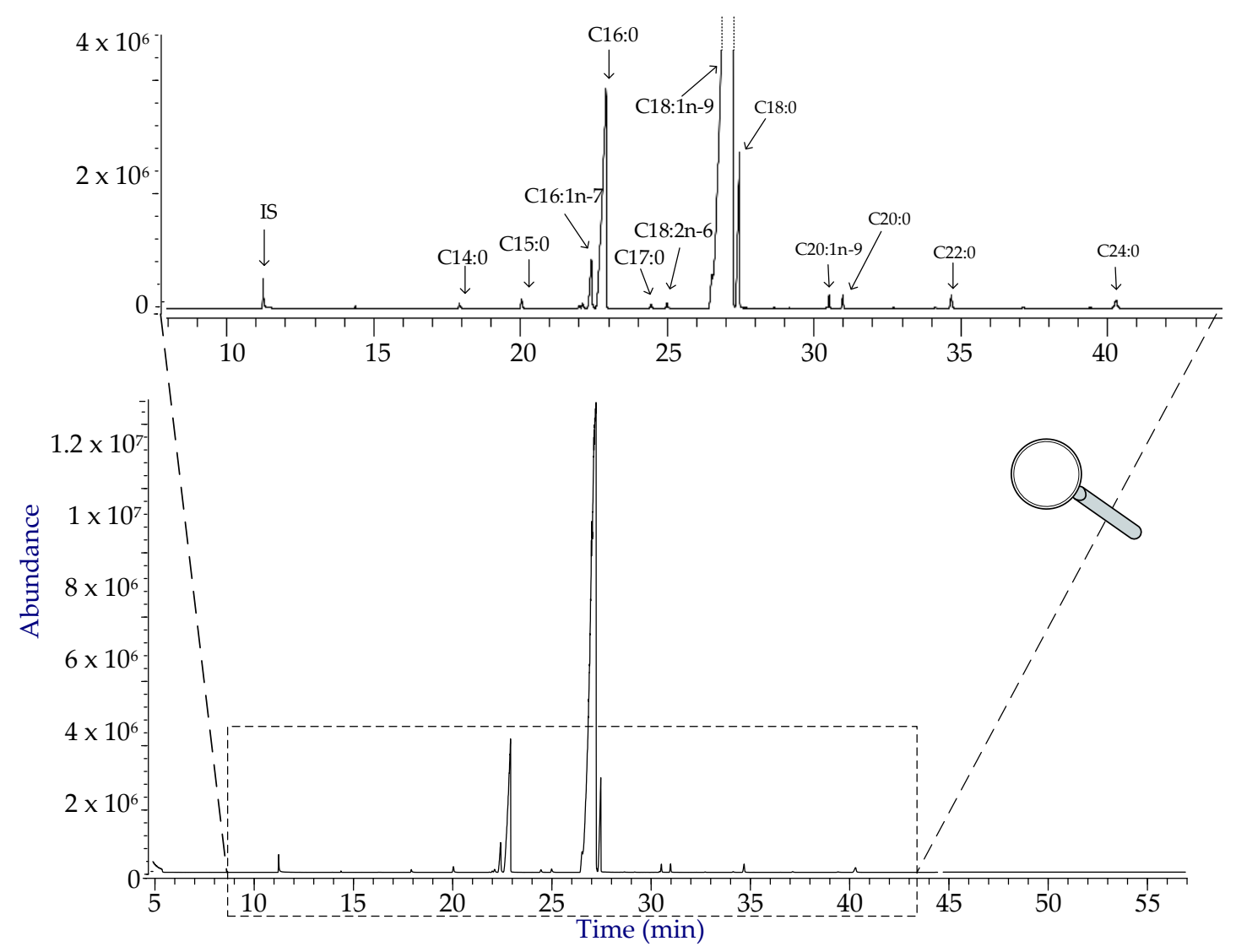

Figure 4. Representative annotated total ion chromatogram (TIC) of FAMEs in samples of Ganoderma lucidum spores.

Table 2 shows complete lipid profiles corresponding to the fatty acid chains of triglycerides in the form of percentage concentrations and the corresponding standard deviations (SD).

Table 2. Fatty acids composition (percentage of FAMEs) contained in samples of Ganoderma lucidum obtained with different extraction processes.

\begin{tabular}{|c|c|c|c|c|c|}
\hline & Name $^{1}$ & $\begin{array}{c}\text { Extraction with } \\
n \text {-Hexane }\left(\% \pm \mathrm{SD}^{2}\right)\end{array}$ & $\begin{array}{c}\text { Extraction in } \\
\text { Soxhlet }(\% \pm \mathrm{SD})\end{array}$ & $\begin{array}{l}\text { Reflux Extraction with } \\
\text { Chloroform }(\% \pm \text { SD) }\end{array}$ & $\begin{array}{l}\text { Commercial Liquid } \\
\text { Extract }(\% \pm \text { SD) }\end{array}$ \\
\hline C14:0 & Myristic acid & $0.14 \pm 0.03$ & $0.24 \pm 0.06$ & $0.14 \pm 0.03$ & $0.09 \pm 0.04$ \\
\hline C15:0 & - & $0.55 \pm 0.03$ & $1.01 \pm 0.05$ & $0.61 \pm 0.03$ & $0.51 \pm 0.05$ \\
\hline C16:1n-7 & Palmitoleic acid & $1.4 \pm 0.15$ & $5.83 \pm 0.07$ & $4.3 \pm 0.4$ & $2.3 \pm 0.3$ \\
\hline C16:0 & Palmitic acid & $18.2 \pm 0.15$ & $21.3 \pm 0.24$ & $17.7 \pm 0.21$ & $16.3 \pm 0.2$ \\
\hline $\mathrm{C} 17: 0$ & Margaric acid & $0.55 \pm 0.02$ & $0.80 \pm 0.03$ & $0.39 \pm 0.02$ & $0.33 \pm 0.03$ \\
\hline$C 18: 2 n-6$ & Linoleic acid & $3.19 \pm 0.03$ & $3.00 \pm 0.03$ & $2.68 \pm 0.03$ & $9.5 \pm 0.10$ \\
\hline C18:1n-9 & Oleic acid & $68.4 \pm 0.97$ & $60.1 \pm 0.84$ & $66.9 \pm 0.90$ & $65.4 \pm 0.91$ \\
\hline $\mathrm{C} 18: 0$ & Stearic acid & $5.77 \pm 0.03$ & $5.94 \pm 0.04$ & $5.52 \pm 0.04$ & $4.38 \pm 0.03$ \\
\hline C20:1n-9 & Gadoleic acid & $0.52 \pm 0.02$ & $0.61 \pm 0.03$ & $0.54 \pm 0.02$ & $0.45 \pm 0.03$ \\
\hline C20:0 & Arachidic acid & $0.45 \pm 0.02$ & $0.56 \pm 0.05$ & $0.50 \pm 0.03$ & $0.42 \pm 0.04$ \\
\hline C22:0 & Behenic acid & $0.48 \pm 0.02$ & $0.41 \pm 0.04$ & $0.47 \pm 0.02$ & $0.28 \pm 0.03$ \\
\hline C24:0 & Lignoceric acid & $0.30 \pm 0.02$ & $0.11 \pm 0.03$ & $0.32 \pm 0.01$ & $0.09 \pm 0.03$ \\
\hline
\end{tabular}

${ }^{1}$ fatty acids analyzed via GC-MS as methyl esters; ${ }^{2} \mathrm{SD}=$ standard deviation.

Reported SDs were evaluated by first calculating the standard deviation of each target analyte concentration by using the standard deviation $s_{y / x}$ of the signal about the regression line. $s_{y / x}$ is 
a statistic which is commonly called "residual deviation about the regression" and which can be readily obtained from calibration data under the assumption of homoscedastic data [26]. The standard deviations on analyte concentrations are finally converted to the reported standard deviations on percentage by a standard uncertainty propagation formula.

All analyzed samples contain a significant amount of oleic (C18:1n-9) and palmitic (C16:0) acids in the range from $60.1 \%$ to $68.4 \%$ and from $16.3 \%$ to $21.3 \%$, respectively. In the examined samples, stearic (C18:0), palmitoleic (C16:1n-7) and linoleic (C18:2n-6) acids are present in much lower amounts $(<10 \%)$. In addition, a small amount of lignoceric (C24:0), myristic (C14:0) and arachidic (C20:0) acids were detected in all the samples $(<1 \%)$. Interestingly, our findings show that the commercially available liquid extract and the extracts of spores of G. lucidum produced in this study employing different processes, have similar lipid contents as revealed by NMR and GC-MS data.

Comparing the processes adopted to extract the spores (Figure 5), some interesting results can be observed. The extract of spores of G. lucidum obtained through the Soxhlet apparatus in $n$-hexane has the highest amount of palmitic acid (C16:0, 21.3\%), but also the lowest amount of oleic acid (C18:1n-9, $60.1 \%)$. Unlike the examined extracts, the commercial oil is particularly rich in linoleic acid (C18:2n-6, $9.5 \%)$, which is the only polyunsaturated fatty acid detected.

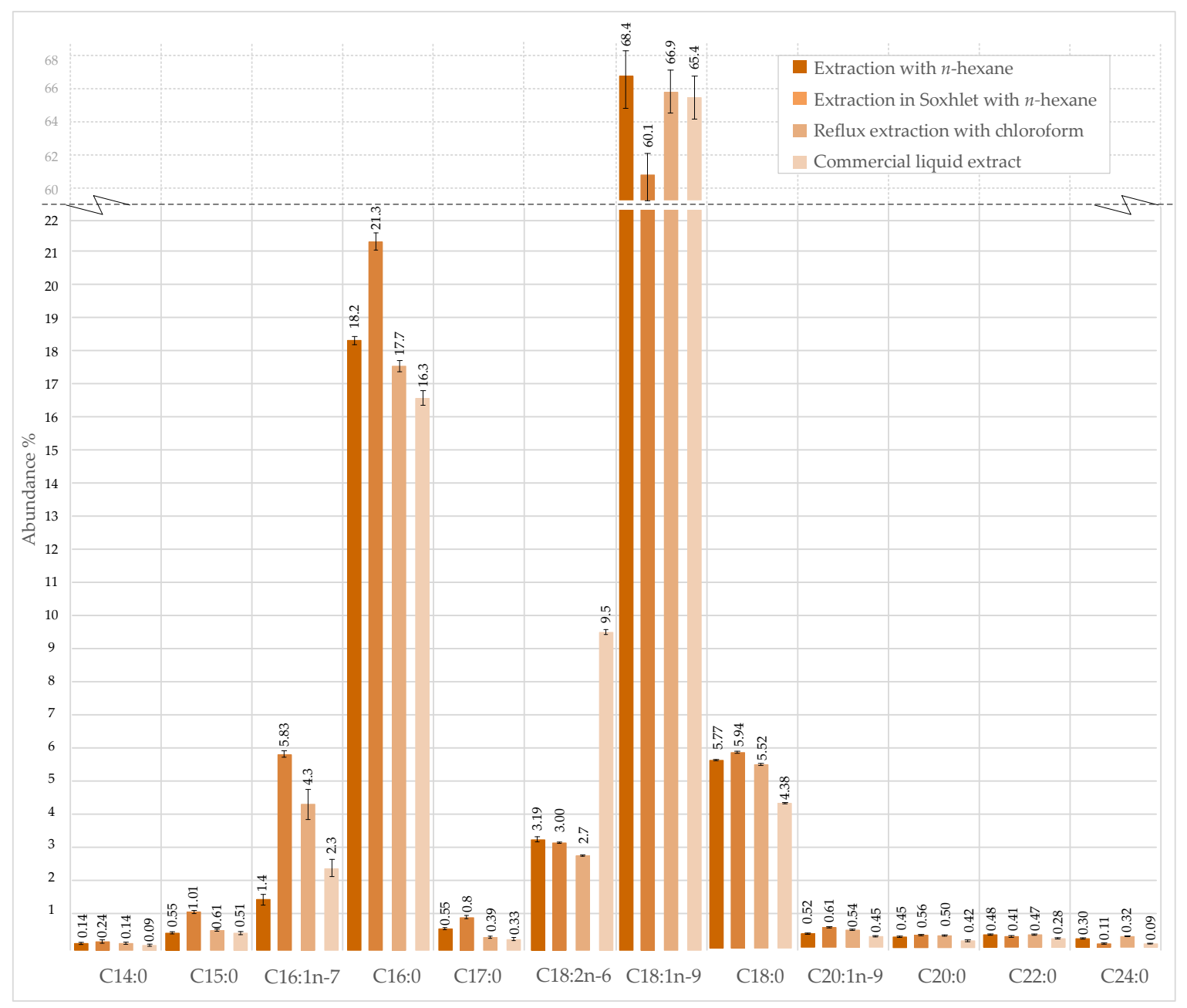

Figure 5. Graphical illustration of fatty acids profiles of lipids from spores of G. lucidum.

The contents of the saturated fatty acids (SFAs), monounsaturated fatty acids (MUFAs) and polyunsaturated fatty acids (PUFAs) were calculated for each extract (Table 3). 
Table 3. Groups of fatty acids from the composition of samples of Ganoderma lucidum obtained with different extraction processes.

\begin{tabular}{|c|c|c|c|c|}
\hline & $\%$ Total FA $^{1}$ & $\% \mathrm{SFA} \pm \mathrm{SD}^{2}$ & $\%$ MUFA \pm SD & $\% \mathrm{PUFA} \pm \mathrm{SD}$ \\
\hline Extraction with $n$-hexane & 26.43 & $26.4 \pm 0.16$ & $70.3 \pm 0.98$ & $3.19 \pm 0.03$ \\
\hline Extraction in Soxhlet & 32.65 & $30.4 \pm 0.27$ & $66.5 \pm 0.84$ & $3.00 \pm 0.03$ \\
\hline Reflux extraction with chloroform & 26.83 & $25.7 \pm 0.22$ & $71.7 \pm 0.99$ & $2.68 \pm 0.03$ \\
\hline Commercial liquid extract & - & $22.0 \pm 0.22$ & $68 \pm 1.00$ & $9.5 \pm 0.1$ \\
\hline
\end{tabular}

MUFAs are the most represented fatty acids in all examined samples, which account for $60 \%-70 \%$ of the total fatty acids. Meanwhile, SFAs are present in approximately $20 \%-30 \%$ of the total fatty acids. As anticipated, the only PUFA present in the samples is linoleic acid contained in the greater amount $(9.5 \%)$ in the commercial oil of G. lucidum (Figure 6).

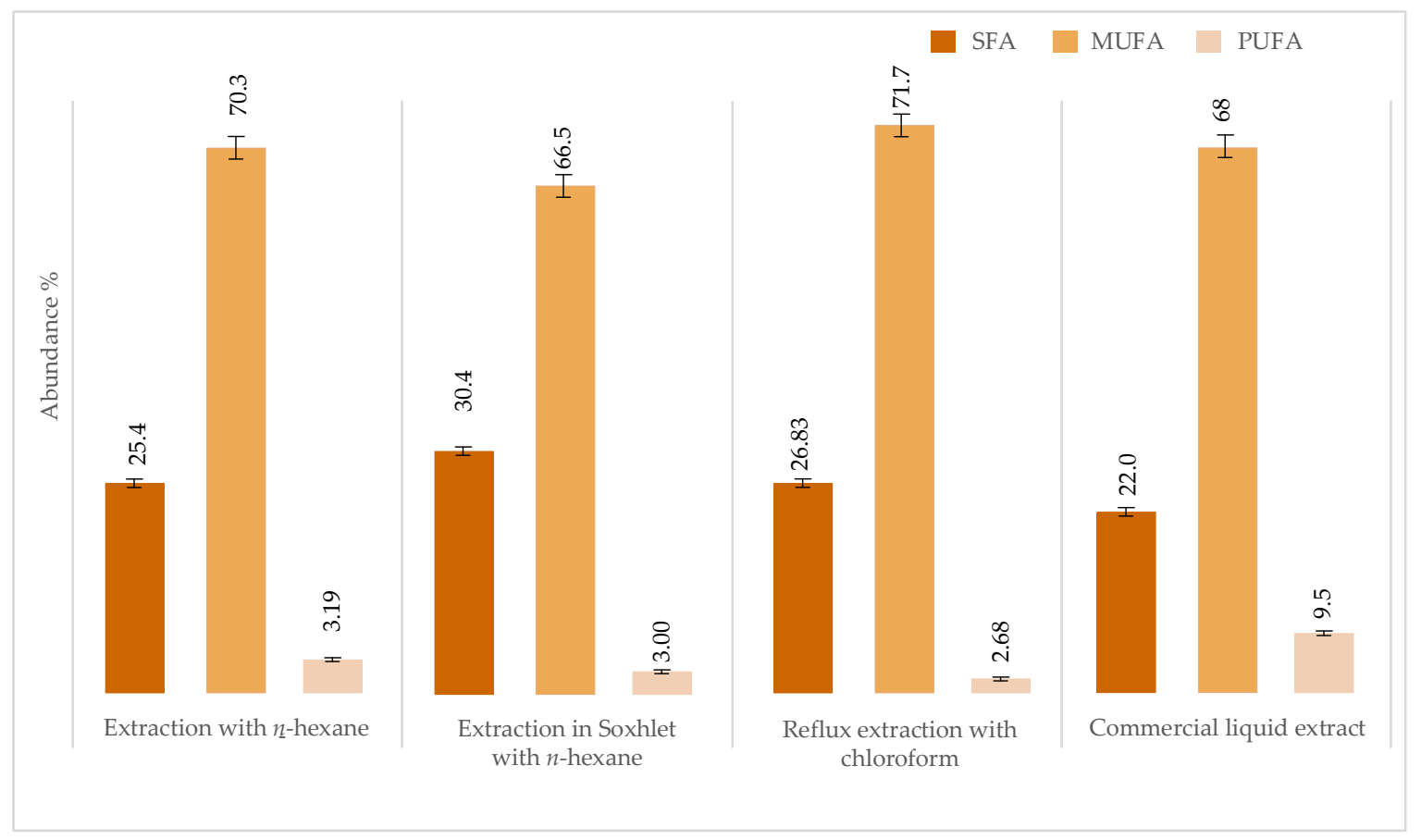

Figure 6. Graphical illustration of groups of fatty acids from the composition of spores of G. lucidum.

\section{Discussion}

In oriental countries, there is a long and historical tradition of using G. lucidum as a folk remedy for health promotion. Its pharmacological activities [3] are recognized by the American Herbal Pharmacopoeia and Therapeutic Compendium [27]. In fact, this mushroom produces a large variety of bioactive compounds, representing a "factory" of compounds to be used in biomedical field [11,28]. Currently, most therapeutic formulations mainly involve the use of the G. lucidum fruiting body and mycelium, but in recent years, the spores are becoming increasingly interesting, thanks to their beneficial effects and innovative extraction techniques [4,14]. The main components of G. lucidum spores are triterpenes, polysaccharides and triglycerides [14].

In this study, analyses of lipid composition of G. lucidum spores were performed comparing different extraction processes. To achieve this goal, we optimized the analytical methodology based on the identification and quantification of FAMEs by GC-MS. The optimization of the method required some adjustment of the temperature ramp of GC-MS to obtain optimal conditions, best peak resolution and the minimum run time. 
Interestingly, our findings show that the procedures used (i.e., extraction with $n$-hexane, extraction in Soxhlet with $n$-hexane, reflux extraction with chloroform) are economical and convenient, in terms of equipment costs, management of the instrumentation and request for qualified personnel for their use. Furthermore, they are easy to implement and allow to produce extracts with a lipid composition similar to the one detected with hard strategies. In this respect, a commercially available liquid extract of G. lucidum obtained with supercritical $\mathrm{CO}_{2}$ extraction was also analyzed. Furthermore, Liu and co-workers [16] reported the extraction and detection of fatty acids in triglycerides from spores of G. lucidum obtained with an extraction process conducted ultrasonically with $\mathrm{CH}_{2} \mathrm{Cl}_{2}$ for $2 \mathrm{~h}$. Our findings are in accordance with the constituents previously detected in spores of G. lucidum [16], but the oleic acid amount is generally higher in the extracts produced in this work, in particular when the spores were extracted with reflux with chloroform $(66.9 \%)$ or extracted with $n$-hexane $(68.4 \%)$.

The beneficial effects of spores of G. lucidum may be related to the synergic action of the fatty acids in triglycerides and in particular to the high abundance of oleic acid, which properties have been extensively reviewed [29]. In fact, oils rich in oleic acid is supposed to present diverse physiological functions confirmed by several studies on its help in cancer, autoimmune and inflammatory diseases [30,31]. Controversial studies have reported potential biologic effects of the second most abundant fatty acid (i.e., palmitic acid) in the extract of spores of G. lucidum [32]. In this respect, the percentage of palmitic acid is approximately $17 \%-18 \%$ in the extract obtained with $n$-hexane, reflux with chloroform and commercial oil, but is much higher $(21.3 \%)$ when the spores where extracted in Soxhlet.

With reference to the extract yield, the extraction with Soxhlet seems to be the most efficient, among the extraction processes studied, with a yield of $32.65 \%$, but it gives the lower amount of oleic acid $(60.1 \%)$ and the higher amount of palmitic acid $(21.3 \%)$.

\section{Conclusions}

In this work, a GC-MS method for the identification and quantification of FAMEs in triglycerides of G. lucidum spores was successfully optimized, and a comparative study of the most used techniques for the lipid extraction from spores was performed. As revealed by NMR and GC-MS data, conventional extraction procedures (i.e., extraction with $n$-hexane, in Soxhlet apparatus with $n$-hexane and reflux with chloroform) gave similar lipid compositions as hard extraction strategies, such as supercritical $\mathrm{CO}_{2}$ extraction. Our findings demonstrated that the commonly used extraction techniques represent an efficient and feasible tool to obtain extracts from G. lucidum spores. This result is particularly relevant in view of future applications of the qualitative and quantitative study of lipids in G. lucidum spores. In fact, the opportunity to study the lipid composition of spores with simple, low cost and no expensive tools is useful to carry out laboratory studies on different strains, to compare different growth conditions or to investigate effect of abiotic factors on biosynthetic pathway of the lipid component.

Author Contributions: Conceptualization, D.N. and A.A.; methodology, M.M.S., F.S., M.D., D.N. and A.A.; investigation, M.M.S., A.E. and A.A.; data curation, M.M.S., F.S. and A.A.; writing-original draft preparation, M.M.S., M.G.; writing-review and editing, M.M.S., F.S., M.G., M.D., D.N. and A.A.; supervision D.N. and A.A.; project administration, D.N. and A.A.; funding acquisition, D.N. and A.A. All authors have read and agreed to the published version of the manuscript.

Funding: This research received no external funding.

Conflicts of Interest: The authors declare no conflict of interest.

\section{References}

1. Wang, X.C.; Xi, R.J.; Li, Y.; Wang, D.M.; Yao, Y.J. The species identity of the widely cultivated Ganoderma, 'G. lucidum' (Ling-zhi), in China. PLoS ONE 2012, 7, e40857. [PubMed]

2. Li, J.Q.; Zhang, J.H.; Chen, H.M.; Chen, X.D.; Lan, J.; Liu, C. Complete mitochondrial genome of the medicinal mushroom Ganoderma lucidum. PLoS ONE 2013, 8, e72038. 
3. Bishop, K.S.; Kao, C.H.; Xu, Y.; Glucina, M.P.; Paterson, R.R.M.; Ferguson, L.R. From 2000 years of Ganoderma lucidum to recent developments in nutraceuticals. Phytochemistry 2015, 114, 56-65. [CrossRef] [PubMed]

4. Boh, B.; Berovic, M.; Zhang, J.; Zhi-Bin, L. Ganoderma lucidum and its pharmaceutically active compounds. Biotechnol. Annu. Rev. 2007, 13, 265-301. [PubMed]

5. Boh, B. Ganoderma lucidum: A potential for biotechnological production of anti-cancer and immunomodulatory drugs. Recent Pat. Anticancer Drug Discov. 2013, 8, 255-287. [CrossRef] [PubMed]

6. Hsu, K.D.; Cheng, K.C. From nutraceutical to clinical trial: Frontiers in Ganoderma development. Appl. Microbiol. Biotechnol. 2018, 102, 9037-9051. [CrossRef] [PubMed]

7. Siwulski, M.; Sobieralski, K.; Golak-Siwulska, I.; Sokół, S.; Sękara, A. Ganoderma lucidum (Curt.: Fr.) Karst.-health-promoting properties. A review. Herba Pol. 2015, 61, 105-118. [CrossRef]

8. Taofiq, O.; Heleno, S.A.; Calhelha, R.C.; Alves, M.J.; Barros, L.; González-Paramás, A.M.; Borreiro, M.F.; Ferreira, I.C. The potential of Ganoderma lucidum extracts as bioactive ingredients in topical formulations, beyond its nutritional benefits. Food Chem. Toxicol. 2017, 108, 139-147. [CrossRef]

9. Chen, S.D.; Li, X.M.; Yong, T.Q.; Wang, Z.G.; Su, J.Y.; Jiao, C.W.; Xie, Y.Z.; Yang, B.B. Cytotoxic lanostane-type triterpenoids from the fruiting bodies of Ganoderma lucidum and their structure-activity relationships. Oncotarget 2017, 8, 10071-10084. [CrossRef]

10. Cör, D.; Knez, Ž.; Knez Hrnčič, M. Antitumour, antimicrobial, antioxidant and antiacetylcholinesterase effect of Ganoderma lucidum terpenoids and polysaccharides: A review. Molecules 2018, 23, 649.

11. Ahmad, M.F. Ganoderma lucidum: Persuasive biologically active constituents and their health endorsement. Biomedicine 2018, 107, 507-519. [CrossRef] [PubMed]

12. Min, B.S.; Nakamura, N.; Miyashiro, H.; Bae, K.W.; Hattori, M. Triterpenes from the spores of Ganoderma lucidum and their inhibitory activity against HIV-1 protease. Chem. Pharm. Bull. 1998, 46, 1607-1612. [CrossRef] [PubMed]

13. Lin, Z.B.; Wang, P.Y. The pharmacological study of Ganoderma spores and their active components. J. Peking Univ. 2006, 38, 541-547.

14. Soccol, C.R.; Bissoqui, L.Y.; Rodrigues, C.; Rubel, R.; Sella, S.R.; Leifa, F.; Porto de Souza Vandenberghe, L.; Soccol, V.T. Pharmacological properties of biocompounds from spores of the lingzhi or reishi medicinal mushroom Ganoderma lucidum (Agaricomycetes): A review. Int. J. Med. Mushrooms 2016, 18, 757-767. [CrossRef]

15. Xu, J.; Li, P. Researches and application of Ganoderma spores powder. In Ganoderma and Health; Springer: Singapore, 2019; pp. 157-186. ISBN 978-981-13-9866-7.

16. Liu, X.; Xu, S.P.; Wang, J.H.; Yuan, J.P.; Guo, L.X.; Li, X.; Huang, X.N. Characterization of Ganoderma spore lipid by stable carbon isotope analysis: Implications for authentication. Anal. Bioanal. Chem. 2007, 388, 723-731. [CrossRef]

17. Deng, Z.L.; Yuan, J.P.; Zhang, Y.; Xu, X.M.; Wu, C.F.; Peng, J.; Wang, J.H. Fatty acid composition in ergosteryl esters and triglycerides from the fungus Ganoderma lucidum. J. Am. Oil Chem. Soc. 2013, 90, 1495-1502. [CrossRef]

18. Salvatore, M.M.; Ciaravolo, M.; Cirino, P.; Toscano, A.; Salvatore, F.; Gallo, M.; Naviglio, D.; Andolfi, A. Fatty acids from Paracentrotus lividus sea urchin shells obtained via Rapid Solid Liquid Dynamic Extraction (RSLDE). Separations 2019, 6, 50. [CrossRef]

19. NIST Standard Reference Data. Available online: http://www.nist.gov/srd/nistla.cfm (accessed on 12 May 2020).

20. Sparkman, O.D.; Penton, Z.E.; Kitson, F.G. Gas Chromatography and Mass Spectrometry: A Practical Guide, 2nd ed.; Elsevier: Burlington, MA, USA, 2011; ISBN 978-0-12-373628-4.

21. Salvatore, M.M.; Giambra, S.; Naviglio, D.; DellaGreca, M.; Salvatore, F.; Burruano, S.; Andolfi, A. Fatty acids produced by Neofusicoccum vitifusiforme and N. parvum, fungi associated with grapevine botryosphaeria dieback. Agriculture 2018, 8, 189. [CrossRef]

22. AMDIS NET. Available online: http://www.amdis.net/ (accessed on 12 April 2020).

23. Salvatore, M.M.; Nicoletti, R.; Salvatore, F.; Naviglio, D.; Andolfi, A. GC-MS approaches for the screening of metabolites produced by marine-derived Aspergillus. Mar. Chem. 2018, 206, 19-33. [CrossRef]

24. Nieva-Echevarría, B.; Encarnación Goicoechea, M.; Manzanos, J.; Guillén, M.D. A method based on ${ }^{1} \mathrm{H}$ NMR spectral data useful to evaluate the hydrolysis level in complex lipid mixtures. Food Res. Int. 2014, 66, 379-387. [CrossRef] 
25. Miller, J.; Miller, J.C. Statistics and Chemometrics for Analytical Chemistry, 4th ed.; Pearson Education: Harlow, UK, 2018; ISBN 0-131-29192-0.

26. Lavagnini, I.; Magno, F. A statistical overview on univariate calibration, inverse regression, and detection limits: Application to gas chromatography/mass spectrometry technique. Mass Spectrom. Rev. 2007, 26, 1-18. [CrossRef] [PubMed]

27. Sanodiya, B.S.; Thakur, G.S.; Baghel, R.K.; Prasad, G.B.; Bisen, P.S. Ganoderma lucidum: A potent pharmacological macrofungus. Curr. Pharm. Biotechnol. 2009, 10, 717-742. [CrossRef] [PubMed]

28. Baby, S.; Johnson, A.J.; Govindan, B. Secondary metabolites from Ganoderma. Phytochemistry 2015, 114, 66-101. [CrossRef] [PubMed]

29. Sales-Campos, H.; Reis de Souza, P.; Crema Peghini, B.; Santana da Silva, J.; Ribeiro Cardoso, C. An overview of the modulatory effects of oleic acid in health and disease. Mini Rev. Med. Chem. 2013, 13, 201-210. [PubMed]

30. Cardoso, C.R.; Favoreto, S., Jr.; Oliveira, L.L.D.; Vancim, J.O.; Barban, G.B.; Ferraz, D.B.; Silva, J.S.D. Oleic acid modulation of the immune response in wound healing: A new approach for skin repair. Immunobiology 2011, 216, 409-415. [CrossRef] [PubMed]

31. Carrillo, C.; Alonso-Torre, S.R. Antitumor effect of oleic acid; mechanisms of action. A review. Nutr. Hosp. 2012, 27, 1860-1865. [PubMed]

32. Mancini, A.; Imperlini, E.; Nigro, E.; Montagnese, C.; Daniele, A.; Orrù, S.; Buono, P. Biological and nutritional properties of palm oil and palmitic acid: Effects on health. Molecules 2015, 20, 17339-17361. [CrossRef]

(C) 2020 by the authors. Licensee MDPI, Basel, Switzerland. This article is an open access article distributed under the terms and conditions of the Creative Commons Attribution (CC BY) license (http://creativecommons.org/licenses/by/4.0/). 